\title{
BULLYING E O CYBERBULLYING NA ESCOLA
}

\author{
BULLYING AND CYBERBULLYING AT SCHOOL
}

\author{
BULLYING Y CYBERBULLYING EN LA ESCUELA
}

\author{
Francisco Nazareno Oliveira ${ }^{1}$
}

\begin{abstract}
RESUMO
Em pesquisas sobre a violência escolar, o termo Bullying é adotado por diversos países para conceituar comportamentos agressivos e antissociais, compreendido como atitudes invasivas, intencionais praticadas repetidamente, são agressões sem motivos reais tendo uma ou mais pessoas contra outra causando extremo sofrimento. Trazendo como pauta, a reflexão em torno do bullying e cyberbullying e sua prática entre escolares, mostra-se que cabe à escola, nessa perspectiva, assumir o papel de refletir com seus alunos e utilizar de forma responsável e ética os recursos tecnológicos, ressaltando os riscos que o cyberbullying pode representar. Isso pode ser realizado por meio de debates nas salas de aula, seminários, apresentações de notícias relacionadas ao tema e reflexões sobre as imprudências do agressor e as sequelas deixadas na vítima.
\end{abstract}

PALAVRAS-CHAVE: Bullying. Escola. Reflexões.

\begin{abstract}
In research on school violence, the term Bullying is adopted by several countries to conceptualize aggressive and antisocial behaviors, understood as intentional attitudes repeatedly practiced, are aggressions without real motives having one or more people against another causing extreme suffering. Taking as its agenda, the reflection about bullying and cyberbullying and its practice among school children, it is shown that it is up to the school, in this perspective, to assume the role of reflecting with its students and to use in a responsible and ethical way the technological resources, emphasizing the risks that cyberbullying can pose. This can be done through classroom discussions, seminars, news presentations related to the topic and reflections on the aggressor's imprudence and the sequels left on the victim.
\end{abstract}

KEYWORDS: Bullying. School. Reflections.

\section{RESUMEN}

En la investigación sobre la violencia escolar, el término Bullying es adoptado por varios países para conceptualizar comportamientos agresivos y antisociales, entendidos como actitudes intencionales repetidas veces, son agresiones sin motivos reales que tienen una o más personas en contra de otra y causan un sufrimiento extremo. Tomando como su agenda, la reflexión sobre el acoso escolar y el acoso cibernético y su práctica entre los niños de la escuela, se muestra que corresponde a la escuela, desde esta perspectiva, asumir el papel de reflexionar con sus alumnos y utilizarlos de manera responsable y ética. los recursos tecnológicos, enfatizando los riesgos que puede suponer el ciberacoso. Esto se puede hacer a través de discusiones en el aula, seminarios, presentaciones de noticias relacionadas con el tema y reflexiones sobre la imprudencia del agresor y las secuelas que quedan en la víctima..

PALABRAS CLAVE: Intimidación. Colegio. Reflexiones.

\footnotetext{
${ }^{1}$ Mestrado em Educação pelo Atenas College University.
}

\begin{tabular}{c|l|l|l}
\hline Rev. Ciências Humanas & Frederico Westphalen, RS & AOP & Set./dez. 2018 \\
\hline \multicolumn{2}{c|}{ Recebido em: 28/12/2018 } & Aceito em: 04/02/2019
\end{tabular}




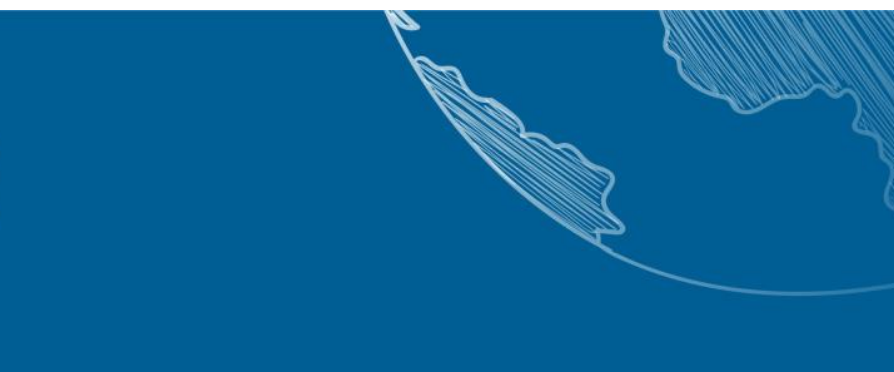

\section{CONSIDERAÇÕES INICIAIS}

O tema em pauta traz uma reflexão importante em seu teor educacional que é o uso ou mau uso das tecnologias que tem se configurado pelos inúmeros casos de processos oriundos, entre outros problemas, do cyberbullying. Trazer este tema para o âmbito da educação tem sua pertinência atrelada ao conhecimento de casos em que ofensas virtuais têm ocorrido muitas vezes, trazendo problemas mais sérios, e, quando acionada a justiça pelas vítimas, a grande maioria dos agressores é composta por adolescentes e jovens.

Os avanços tecnológicos mais facilmente acessíveis a partir da década de 1990, com o advento da globalização, e ainda mais intensificados, também, nesta década, quanto a internet começa a fazer parte direta na vida das pessoas, em que, gradativamente, teve seu uso popularizado, trazem nova dinâmica às relações interpessoais.

Em relação ao âmbito educativo, é nas escolas que, normalmente, se dá início ao cyberbullying através do uso da Internet nas salas de computadores (WILLARD, 2007), através do uso abusivo de celulares ou outros equipamentos pessoais.

É a partir desses pressupostos que se percebe que a escola tem a responsabilidade de garantir um ambiente seguro, com suporte emocional, baseado no respeito por todos, que incentive a aprendizagem, de forma a desenvolver a autoestima, criando um ambiente no qual todos alunos se sintam protegidos dos vários tipos de bullying.

\section{Internet: considerações iniciais}

O nascimento da internet aconteceu em 1969, nos Estados Unidos, interligando laboratórios de pesquisa, sendo uma rede de Departamento de Defesa norte-americana, na época da Guerra Fria, mas, somente em 1987, que a internet foi liberada para uso comercial, tendo seu grande impulso a partir de 1992, quando começou a fazer parte do dia a dia dos americanos. 


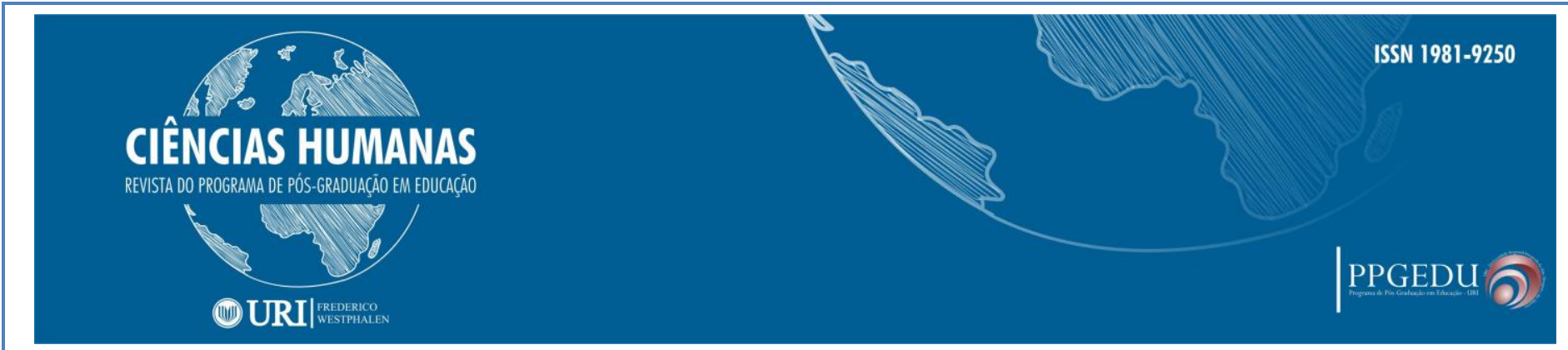

O primeiro acesso à internet, no Brasil, aconteceu em 1991, porém, de forma bem limitada restrita ao mundo científico e acadêmico, utilizado com fins de pesquisa. No Brasil, a internet passou a ficar mais conhecida a partir da segunda metade da década de 90. Em 1995, acontecia o primeiro acesso a internet no país, com pouco mais de cinco mil usuários, mas, funcionando ainda de forma bem restrita, melhorando só a partir de 1997, quando começa a ganhar força, com o surgimento de novos provedores.

Foi, entretanto, somente a partir do ano 2000, em um processo gradativo que a internet começa a se popularizar no Brasil. À proporção que surgiam novos provedores e que o Governo Federal abria caminho para um acesso mais democrático, com o surgimento de alguns serviços grátis, a internet aumentava o número de usuários, terminando a primeira década do século XXI, com milhões de usuários.

Conforme dados da Pesquisa Nacional por Amostra de Domicílios - PNAD (IBGE, 2014), o Brasil, em 2006, tinha pouco mais de 35 milhões de usuários da internet, passando para quase 86 milhões, em 2013, em números cuja tendência é aumentar cada vez mais.

Atualmente, são números difíceis de calcular. Além de terem aumentado consideravelmente, o número de pessoas com computadores em casa, com acesso à internet, ainda se tem alternativas como lan-houses, empreendimento comercial que tem crescido de forma bastante intensificada; o acesso via celular, com tecnologias cada vez mais avançadas; o provimento de escolas (públicas e privadas) com computadores e internet que os alunos podem usar. O que se vê é que a internet, hoje, atinge quase toda uma população, seja como usuário frequente seja circunstancialmente, diante de uma necessidade.

Quando a internet se tornou mais popular mundialmente, na década de 90, o email aparecia como a única forma de comunicação entre os usuários, embora, não tenha evoluído bastante a ponto de poder ser considerada uma rede social. Entretanto, foi através do e-mail que surgiu a necessidade de criar meios de interação mais abrangentes, com mais possibilidades e em tempo real.

Surgem os chats oferecidos por provedores vários. Neles, o usuário poderia se comunicar com outras pessoas, em tempo real, evoluindo para serviços como o MSN 


\section{CIÊNCIAS HUMANAS}

REVISTA DO PROGRAMA DE PÓS-GRADUAĞ̈O EM EDUCAĞ̄o

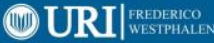

Messenger, na época, um dos instrumentos de troca social via internet mais avançado, permitindo longos bate papo com maior privacidade, troca de arquivos de áudio, vídeo etc.

De acordo com Guedes (2012), as redes sociais começaram, então, a ficarem mais evoluídas, surgindo, assim, o Myspace (2003); o Orkut (2004) o Facebook (2004); O Twitter (2006); o Google+ (2011) entre outros. Alguns serviços ficaram mais específicos, como o caso do Instagram (2010), rede de compartilhamento de foto e vídeo ou o Linkedin (2003), voltado para a divulgação de currículos e oportunidades de empregos, entre outros.

Geralmente, essas redes sociais aparecem, ganham fama, mas, depois perdem espaço para outras. Foi o que aconteceu em relação ao Orkut que perdeu espaço principalmente, para o Facebook. Tendo as duas quase que as mesmas funções, a segunda parece ter sido considerada mais interessante pelos usuários. Assim, em setembro de 2014, o Orkut saiu de cena, ainda existindo, mas, apenas como uma espécie de museu, no qual os usuários podem ver suas postagens e registros antigos. Por enquanto, Facebook, Instagram e, em menor escala, o twitter, pelo menos, no Brasil, são as redes mais populares.

No entanto, algo que tem ganhado bastante espaço e que tem superado as redes acima, são os aplicativos de telefonia móvel, mais especificamente, o mais famoso, o WhatsApp, criado em 2009, comprado pelo criador do Facebook e que, em 2014 estava para atingir a marca de um bilhão de usuários, com seu uso cada vez mais democrático, atingindo praticamente, todas as camadas sociais.

A sua popularidade deve-se ao fato de estar em um tipo de tecnologia bem mais democrática que o computador em suas diversas formas, Dekstop, notebook,., ou seja, o telefone celular e suas funcionalidades, através da plataforma Android, presente em 91\% dos celulares dos brasileiros, de acordo com pesquisa realizada pela Nielsen Ibope, no primeiro semestre de 2014 (CANALTECH, 2014).

São caminhos facilitadores para a interação mas, também, para os crimes cibernéticos, desde ofensas de injúria racial, religiosa, transfóbica, homofóbica, até ameaças, roubo de dados, crimes de pedofilia entre outros. 


\title{
Bullying e violência escolar
}

De acordo com Oliveira e Antonio (2006) o bullying se dá a partir de ações discriminatórias e práticas frequentes de violência no cotidiano escolar, tratando-se de um tipo de exclusão social capaz de oprimir, intimidar e machucar aos poucos, sem nunca ser declarada de fato.

Segundo Fante (2005, p.16):

\begin{abstract}
Na maioria das vezes as vítimas sofrem caladas por vergonha de se exporem ou por medo de represálias dos seus agressores, tornando-se reféns de emoções traumáticas destrutivas, como medo, insegurança, raiva, pensamentos de vingança e de suicídio, além de fobias sociais e outras reações que impedem seu bom desenvolvimento escolar.
\end{abstract}

Analisando o problema sob a perspectiva das escolas, Lopes Neto (2005) observam que se trata de um fenômeno complexo, muitas vezes banalizado ou confundido com agressão e indisciplina e que podem estar associados a fatores econômicos, sociais, culturais, aspectos inatos de comportamento e influências familiares, de amigos, da escola e da comunidade.

Fávaro (2009) realizou um estudo em uma escola pública estadual, localizada no município de Turvo - SC. no qual fez um levantamento das consequências que o fenômeno bullying causa em seus envolvidos (agressor, vítima e testemunhas). A autora constatou a predominância de dificuldades de aprendizado, e analisou que:

As consequências do Bullying são inúmeras e afetam todas as crianças tanto as vítimas, como as testemunhas e os agressores. Os pais e os educadores precisam ficar atentos a qualquer modificação no comportamento, pois esse fenômeno pode prejudicar a aprendizagem dos alunos já que ele, muitas vezes, age dessa maneira devido ao fato de vir de uma família desestruturada, que muitas vezes não lhe dá atenção, e na tentativa de consegui-la esta criança passa a praticar o Bullying. (FAVARO, 2009, p.23)

Em pesquisas sobre a violência escolar, o termo Bullying é adotado por diversos países para conceituar comportamentos agressivos e antissociais, compreendido como atitudes invasivas, intencionais praticadas repetidamente, são agressões sem motivos 


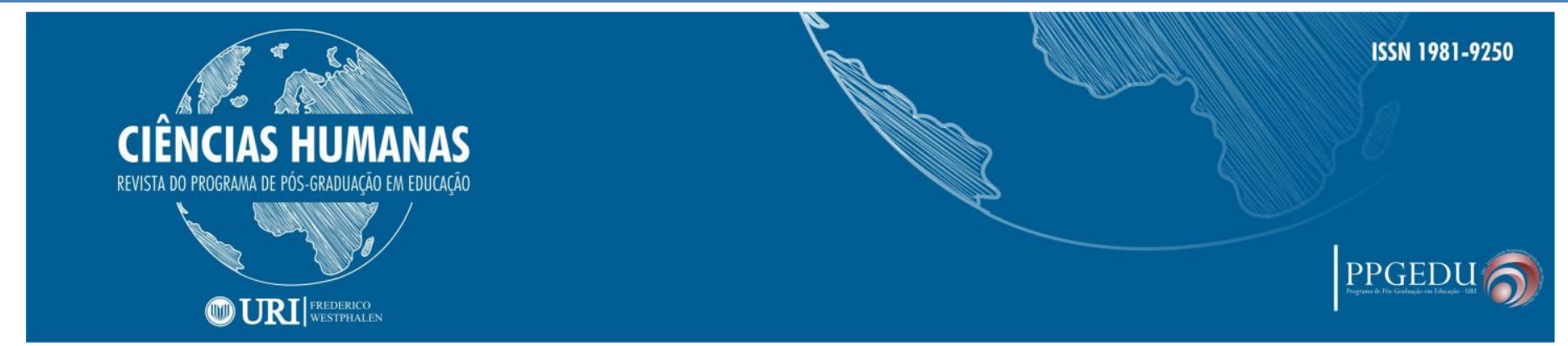

reais tendo uma ou mais pessoas contra outra causando extremo sofrimento. (SANTOS;

PINHEIRO, 2013)

O que distingue esses processos de outras formas de agressão, segundo Wendt et al. (2010), "são as características que lhe conferem um caráter ordenado, sistemático e recorrente".

Contudo, Maldonado (2011), analisa que no cyberbullying:

\begin{abstract}
Os ataques poderosos e destrutivos podem ser feitos sem a característica da repetição, porque entra aí outro elemento que produz efeitos devastadores: a rapidez da propagação da mensagem que, em poucos minutos, atinge uma plateia de proporções incomensuráveis. Isso potencializa dramaticamente a vergonha, o pavor e a humilhação, o que faz com que algumas pessoas se sintam sem saída, a ponto de, desesperadas, tentarem o suicídio.
\end{abstract}

Segundo Fante e Pedra (2008), são exemplos de cyberbullying mensagens instantâneas disparadas para espalhar intrigas e fofocas, bem como fotografias adulteradas e publicadas como piadas; muitas vezes votações são realizadas por meio de sites para eleger qual o colega que possui mais características estereotipadas.

Fante e Pedra (2008, p. 106) sugerem então, que:

A escola precisa capacitar seus profissionais para observação, identificação, diagnóstico, intervenção e encaminhamentos corretos, levar o tema à discussão com toda a comunidade escolar e traçar estratégias preventivas que sejam capazes de fazer frente ao fenômeno.

E complementam ainda, que se deve também, adotar no contexto escolar, a formação de equipes capazes de articular políticas preventivas e qualificar seus colaboradores para atuar de forma segura, sem correr o risco de ameaças desnecessárias.

\title{
Como combater: papel da escola
}

Meier e Rolim (2013, p. 96), veem a prevenção como o melhor "recurso e justificam:

\begin{tabular}{c|l|l|l}
\hline Rev. Ciências Humanas & Frederico Westphalen, RS & AOP & Set./dez. 2018 \\
\hline \multicolumn{2}{c}{ Recebido em: 28/12/2018 } & \multicolumn{3}{c}{ Aceito em: 04/02/2019 } \\
\hline
\end{tabular}




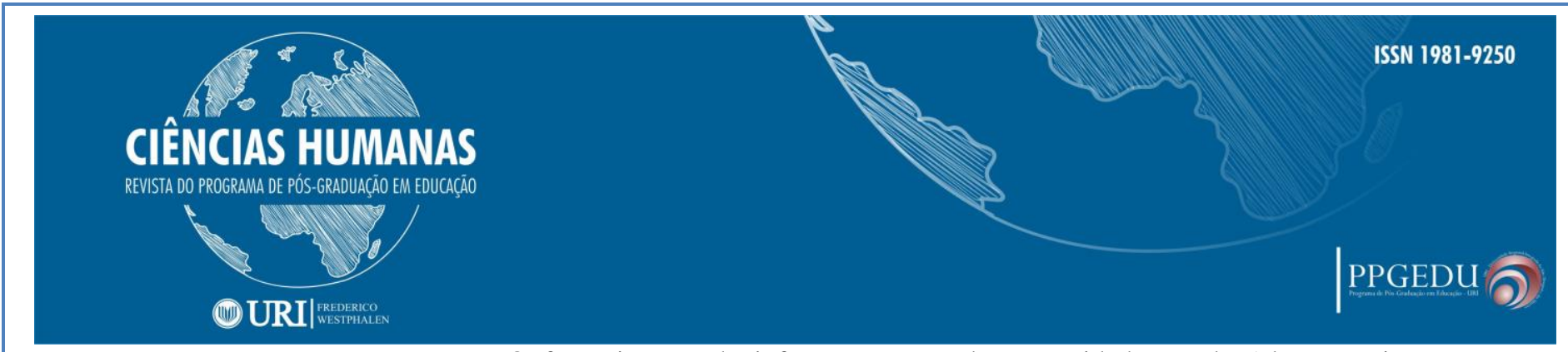

O fornecimento de informações a toda comunidade escola (alunos, pais, professores e demais funcionários), rompe-se a primeira das armadilhas desse fenômeno: o silêncio. [...] uma excelente estratégia é a promoção de debates, de momentos de troca de experiências e de palestras de qualidade. (MEIER; ROLIM, 2013, p. 96)

Sobre a prevenção, Fante e Pedra (2008) explicam que esta começa pelo conhecimento, fazendo-se necessário que a escola reconheça a presença dessa violência e esteja ciente dos seus danos para o desenvolvimento socioeducacional dos alunos. Cabe, então, à escola, nessa perspectiva, assumir o papel de refletir com seus alunos e utilizar de forma responsável e ética os recursos tecnológicos, ressaltando os riscos que o cyberbullying pode representar. Isso pode ser realizado por meio de debates nas salas de aula, seminários, apresentações de notícias relacionadas ao tema e reflexões sobre as imprudências do agressor e as sequelas deixadas na vítima.

Segundo Meier e Rolim (2013, p. 100):

É preciso ensinar os alunos sobre o uso responsável da internet, do celular e de outras tecnologias. Muitas crianças têm pais que não possuem uma clara noção do perigo que a rede mundial de comunicação pode trazer aos seus filhos e, por isso, deixam de orientá-los. Os educadores podem ajudar nessa tarefa, mostrando a eles a seriedade e a responsabilidade necessárias ao se publicar qualquer informação a respeito de si mesmo (e de terceiros) na internet.

Não se pode esquecer, também, a fundamental importância dos responsáveis pelos alunos nesse processo, trabalhando de forma a envolve-los, por meio da sensibilização, orientação aos filhos, observação das ações dos mesmos, comportamentos e a forma como utilizam os recursos tecnológicos, evitando, assim, as penalidades previstas em Lei. Por fim, os professores precisam estar atentos, pois tudo começa com uma piadinha dentro da sala de aula e vira assunto nos sites de relacionamentos (FANTE; PEDRA, 2008).

\section{Considerações Finais}

Observa-se, que, em um quadro geral, a vida das pessoas tem sido bastante facilitada com o boom tecnológico em seu cotidiano. Mas, ao que parece, bônus não

\begin{tabular}{c|c|c|l}
\hline Rev. Ciências Humanas & Frederico Westphalen, RS & AOP & Set./dez. 2018 \\
\hline Recebido em: 28/12/2018 & Aceito em: 04/02/2019 \\
\hline
\end{tabular}




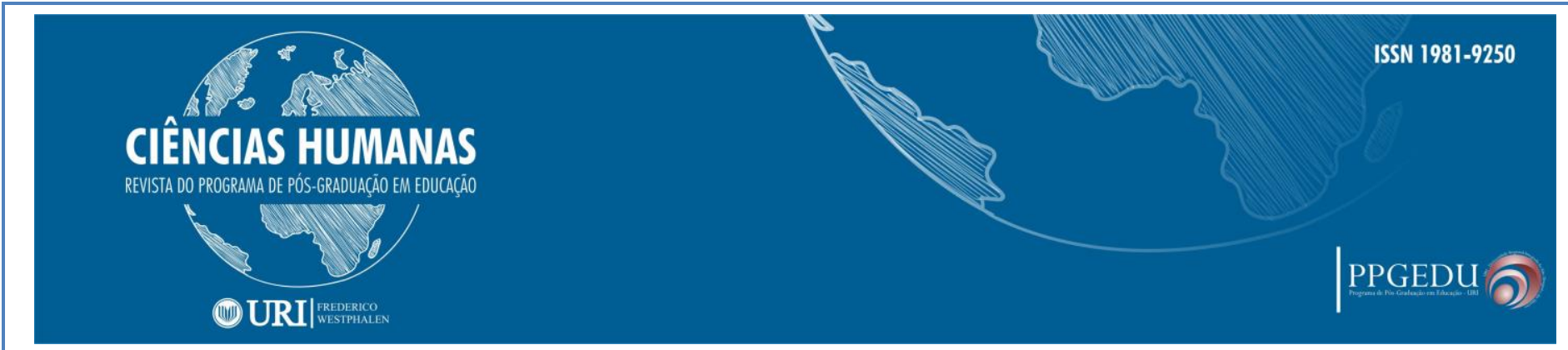

vem sem ônus. Reiterando o que já foi mencionado no início, se por um lado, os espaços virtuais trouxeram maior comodidade no cotidiano das pessoas, diminuindo distâncias, dinamizando as relações sociais, comerciais etc., por outro, muitas dores de cabeça são oriundas desses meios.

Diante do que foi exposto, constata-se que é importante analisar o problema a partir de um projeto curricular voltado para um trabalho com os alunos. Estes estão inseridos em um contexto que às vezes pode até não se tornar favorável no ambiente escolar. Problemas familiares, baixo poder aquisitivo, problemas psicológicos e bullying, por exemplo, são situações que o currículo oculto traz como um desafio que se faz necessário saber enfrentar dia após dia, direta ou indiretamente.

\section{Referências}

CANALTECH. Android está em $91 \%$ dos celulares vendidos no Brasil. iOS está em apenas 2\%. Artigo da redação. Publicado em 23/09/2014. Disponível em: http://canaltech.com.br/noticia/mobile/Android-esta-em-91-dos-celulares-vendidos-noBrasil-iOS-esta-em-apenas-2/. Acesso em 24/10/2017.

FANTE, C.; PEDRA, J. A. Bullying escolar. Porto Alegre: Artmed, 2008.

FANTE, Cleo. O fenômeno bullying: como prevenir nas escolas e educar para a paz. 2. ed. Campina, SP: Verus editora, 2005.

FAVARO, T.N. Bullying e aprendizagem: desafios e possibilidades no ambiente escolar. 47 f. Monografia (Trabalho de Conclusão de Curso em Pedagogia) Universidade do Extremo Sul Catarinense, Criciúma, 2009.

IBGE - Instituto Brasileiro de Geografia e Estatística. Pesquisa Nacional por Amostra de Domicílios - PNAD 2013. Brasília: IBGE/PNAD/Ministério das Comunicações, 2014.

MALDONADO, Maria Tereza. Bullying e ciberbullying: o que fazemos com o que fazem conosco? São Paulo: Moderna, 2011.

MEIER, M.; ROLIM, J. Bullying sem blá-blá-blá. Curitiba: Intersaberes, 2013.

SANTOS, A. dos R.; PINHEIRO, R. O bullying como crime contra a dignidade da pessoa humana. In: SEMINÁRIO DE IC DO ICESP/PROMOVE, 2., 2013, Brasília. Anais do Simpósio de TCC. Brasília, 2013. 
WENDT, G. W.; CAMPOS, D. M. de; LISBOA, C. S. de M. Agressão entre pares e vitimização no contexto escolar: bullying, cyberbullying e os desafios para a educação contemporânea. Caderno de Psicopedagogia, São Paulo, v. 8, n. 14, p. 41-52, out. 2010 .

WILLARD, Nancy. Educator's guide to cyberbullying and cyberthreats. 2007. Disponível em: http://cyberbully.org/. Acesso em: jan/2018. 